\title{
Effects of iodine supplementation during pregnancy on pregnant women and their offspring: a systematic review and meta-analysis of trials over the past 3 decades
}

\section{Pantea Nazeri', Mamak Shariat ${ }^{2}$ and Fereidoun Azizi ${ }^{3}$}

${ }^{1}$ Family Health Institute, Breastfeeding Research Center, Tehran University of Medical Sciences, Tehran, Iran, ${ }^{2}$ Family Health Institute, Maternal, Fetal and Neonatal Research Center, Tehran University of Medical Sciences, Tehran, Iran, and ${ }^{3}$ Endocrine Research Center, Research Institute for Endocrine Sciences, Shahid Beheshti University of Medical Sciences, Tehran, Iran
Correspondence should be addressed to F Azizi

Email

azizi@endocrine.ac.ir

\begin{abstract}
Objective: The current systematic review aimed to provide comprehensive data on the effects of iodine supplementation in pregnancy and investigate its potential benefits on infant growth parameters and neurocognitive development using meta-analysis.

Methods: A systematic review was conducted on trials published from January 1989 to December 2019 by searching MEDLINE, Web of Science, the Cochrane Library, Scopus, and Google Scholar. For most maternal and neonatal outcomes, a narrative synthesis of the data was performed. For birth anthropometric measurements and infant neurocognitive outcomes, the pooled standardized mean differences (SMDs) with 95\% Cls were estimated using fixed/random effect models.

Results: Fourteen trials were eligible for inclusion in the systematic review, of which five trials were included in the meta-analysis. Although the findings of different thyroid parameters are inconclusive, more consistent evidence showed that iodine supplementation could prevent the increase in thyroglobulin concentration during pregnancy. In the meta-analysis, no differences were found in weight $(-0.11$ ( $95 \% \mathrm{Cl}:-0.23$ to 0.01$)$ ), length $(-0.06$ ( $95 \% \mathrm{Cl}:-0.21$ to 0.09$)$ ), and head circumference $(0.26(95 \% \mathrm{Cl}:-0.35$ to 0.88$)$ ) at birth, or in cognitive $(0.07(95 \% \mathrm{Cl}:-0.07$ to 0.20$)$ ), language $(0.06(95 \% \mathrm{Cl}:-0.22$ to 0.35$))$, and motor $(0.07(95 \% \mathrm{Cl}:-0.06$ to 0.21$))$ development during the first 2 years of life in infants between the iodine-supplemented and control groups.

Conclusion: lodine supplementation during pregnancy can improve the iodine status in pregnant women and their offspring; however, according to our meta-analysis, there was no evidence of improved growth or neurodevelopmental outcomes in infants of iodine-supplemented mothers.
\end{abstract}

\section{Introduction}

Iodine, an essential component of thyroid hormones, plays a key role in the overall growth of the body and development of the CNS of the fetus and infant (1). During pregnancy, the need for iodine increases significantly from $150 \mu \mathrm{g} /$ day in non-pregnant adult women to $250 \mu \mathrm{g} /$ day because of increased thyroid hormone synthesis, iodine
Published by Bioscientifica Ltd. 
transfer to the fetus, and increased excretion of iodine through urine $(2,3)$. Therefore, inadequate iodine intake during this critical period results in impaired thyroid hormone synthesis, subsequent growth retardation, and irreversible brain damage $(4,5,6)$.

In countries with effective salt iodization programs, although school children attain sufficient iodine status, abundant evidence indicates that pregnant women and lactating mothers have inadequate levels of iodine $(7,8$, 9 ). Iodized salt may not always be a sufficient source of iodine to meet the minimum requirements of the most vulnerable groups (i.e. pregnant and lactating women and infants). Therefore, leading international health authorities, such as the American Thyroid Association (10), the Endocrine Society (11), and the American Academy of Pediatrics (12), recommend that pregnant and lactating women or those who are planning for pregnancy should take supplements containing $150 \mu \mathrm{g}$ of iodine to prevent deficiency. The correction of severe iodine deficiency through iodine supplementation or food fortification programs results in improved clinical outcomes (13). However, results of studies conducted on the impacts of iodine supplementation in mildly to-moderately iodine-deficient pregnant women are inconsistent (14). Observational cohorts reported significant positive consequences (both health and economic) of correcting iodine deficiency in pregnant women. Meanwhile, the findings of clinical trials are controversial (15). Still, there are debates regarding the benefits of iodine supplementation, alone or in combination with other vitamins and minerals, in women before conception or during pregnancy.

Although iodine supplementation is generally considered a safe intervention for pregnant women, some observational studies report that it might have risks. For instance, a cohort study conducted in Spain showed lower psychomotor development in infants whose mothers received $\geq 150 \mu \mathrm{g} /$ day of iodine supplements $(16,17)$. Another study on pregnant women who received excessive iodine reported an increased risk of developing thyroid disorders in both mothers and neonates (18). However, only few clinical trials have investigated the adverse effect(s) of iodine supplementation during pregnancy. It is still uncertain whether the recommended dose of iodine supplementation is safe for pregnant women living in iodine-sufficient areas.

There are several reviews on iodine supplementation for pregnant women or during the postpartum period. However, most are narrative synthesis of the findings of observational studies or systematic reviews of clinical trials with a focus on one or more clinical outcome (s), which cannot provide strong evidence or comprehensive data on short- and long-term effects of iodine supplementation during pregnancy. Therefore, this study, which is a systematic review of trials, aimed to provide a comprehensive overview of evidence regarding the effects of iodine supplementation in pregnant women and their offspring and investigate its potential benefits on infant growth parameters and neurocognitive development using meta-analysis.

\section{Methods}

The current study followed the Preferred Reporting Items for Systematic Reviews and Meta-analyses (PRISMA) guidelines (19).

\section{Search strategy}

All articles published from January 1989 to December 2019 were systematically searched using the MEDLINE/ PubMed (National Library of Medicine), Web of Science citation indexing service (produced by the Institute for Scientific Information), Cochrane Library (Cochrane Database of Systematic Reviews, Cochrane Central Register of Controlled Trials (CENTRAL), Cochrane Methodology Register), and Scopus databases, and Google and Google Scholar search engines. Details of the search strategy are presented in Supplementary data (see section on supplementary materials given at the end of this article). To collate additional evidence, we conducted a manual search using the reference lists of original articles and relevant reviews. All searched articles were entered into EndNote to merge retrieved citations, discard duplicates, and simplify the review process.

\section{Study selection and data extraction}

The titles and abstracts of studies were screened by two independent investigators (PN and MS) to exclude irrelevant studies. The full texts of remaining studies were retrieved, and relevant articles were identified. The inclusion criteria were as follows: human studies; healthy pregnant women as participants; randomizedcontrolled trials or quasi-randomized trials, which investigated the effects of iodine supplementation during pregnancy; administration of iodine supplements to participants, regardless of the iodine status of the study population, iodine compound, dose, frequency or 
duration, and including an appropriate control group, which comprised participants receiving a significantly lower dose of supplements, placebo, or no supplements; urinary iodine concentration (UIC), thyroid hormones and volume, pregnancy or neonatal complications, or growth parameters or neurocognitive development were determined. The exclusion criteria were as follows: animal studies, non-English articles, pregnant women with thyroid disorders as study sample, and any duplicate publications or incomplete articles. The PICOS (participants, interventions, comparisons, outcomes, study design) criteria are shown in Table 1.

Two investigators (PN and MS) independently extracted the trial data using standardized forms specially developed for the current review. Any disagreements were resolved through discussion or consulted with a third investigator (FA). The following data were extracted: first author, year of publication, country or location of the study, sample size (i.e. the number of pregnant women), baseline iodine status according to the population median UIC, and iodine supplementation (initiation, type, dose, and duration). The investigated outcomes were maternal and neonatal iodine status, different thyroid parameters, and clinical complications and growth parameters at birth and infant neurocognitive development following iodine supplementation.

\section{Risk of bias assessment}

The Cochrane Collaboration tool was used to assess the risk of bias of each included trial (20). The following criteria were considered: (i) random sequence generation, (ii) allocation concealment, (iii) blinding of participants and personnel, (iv) blinding of outcome assessment, (v) incomplete outcome data, (vi) selective outcome reporting, and (vii) other possible sources of bias. Studies were judged as low, high, or unclear risk of bias for each item separately.

Table 1 PICOS criteria for inclusion of trials.

\begin{tabular}{|c|c|}
\hline $\begin{array}{l}\text { Population } \\
\text { Intervention }\end{array}$ & $\begin{array}{l}\text { Healthy pregnant women and their infants } \\
\text { lodine supplementation }\end{array}$ \\
\hline Comparison & lodine group(s) vs control group(s) \\
\hline Outcomes & $\begin{array}{l}\text { - } \text { lodine status } \\
\text { - Different thyroid parameters } \\
\text { - } \text { Growth status } \\
\text { - Neurocognitive development } \\
\text { - Pregnancy or neonatal complications }\end{array}$ \\
\hline Study design & $\begin{array}{l}\text { Randomized or quasi-randomized } \\
\text { controlled trials }\end{array}$ \\
\hline
\end{tabular}

\section{Statistical analysis}

A narrative synthesis of the data was performed for most maternal and neonatal outcomes because of substantial clinical and statistical heterogeneity among trials included in the systematic review. Moreover, a meta-analysis on qualified trials was also performed to assess the effects of iodine supplementation on birth growth parameters and infant neurocognitive development during the first 2 years of life. We calculated the mean values and S.D. of birth weight, length and head circumference as well as cognition, language, and motor scores of infants using the median, lower and upper interquartile range (IQR), range, or $95 \% \mathrm{CI}$ if the mean and s.D. were not directly reported. The effects of the intervention were measured using the standardized mean difference (SMD) estimations. Pooled-SMDs and 95\% CIs were calculated for all effect sizes and weighted according to the sample size of the individual studies, using fixed/random effect models based on the absence/presence of heterogeneity. Statistical heterogeneity was also evaluated using Q Cochrane and the $I^{2}$ index. Publication bias tests were not conducted $(n<10)$. Analyses were performed using Stata software, version 12.0 (Stata Corp).

\section{Results}

\section{Study selection and characteristics}

The literature search and study selection process are shown in Fig. 1. Of 385 potential studies identified during the initial search, 35 appeared relevant and, therefore, were fully assessed for inclusion. After exclusion of studies that they investigated the effect of multiple micronutrient supplementation other than iodine $(n=8)$ or were not randomized or quasi-randomized controlled trials $(n=13), 14$ were eligible for the systematic review. The general characteristics of the included trials are described in Table 2. The included trials were conducted in Africa (Ghana) (21), Asia (Bangladesh, India, and Thailand) (22, 23), Europe (Belgium, Denmark, France, Germany, Spain, and Italy) $(24,25,26,27,28,29,30,31,32,33,34)$, and the southwest Pacific Ocean (Australia) (35). Based on data reported by the Iodine Global Network in 2017 (36), the following countries were faced with iodine sufficiency before the implementation of the intervention: Ghana (2011), Bangladesh (2011-12), India (2014-15), Thailand (2012), France (2006-07), Spain (2011-12), and Australia (2011-12). The sample size in the included trials ranged from 35 to 1159 participants. The median of the maternal 


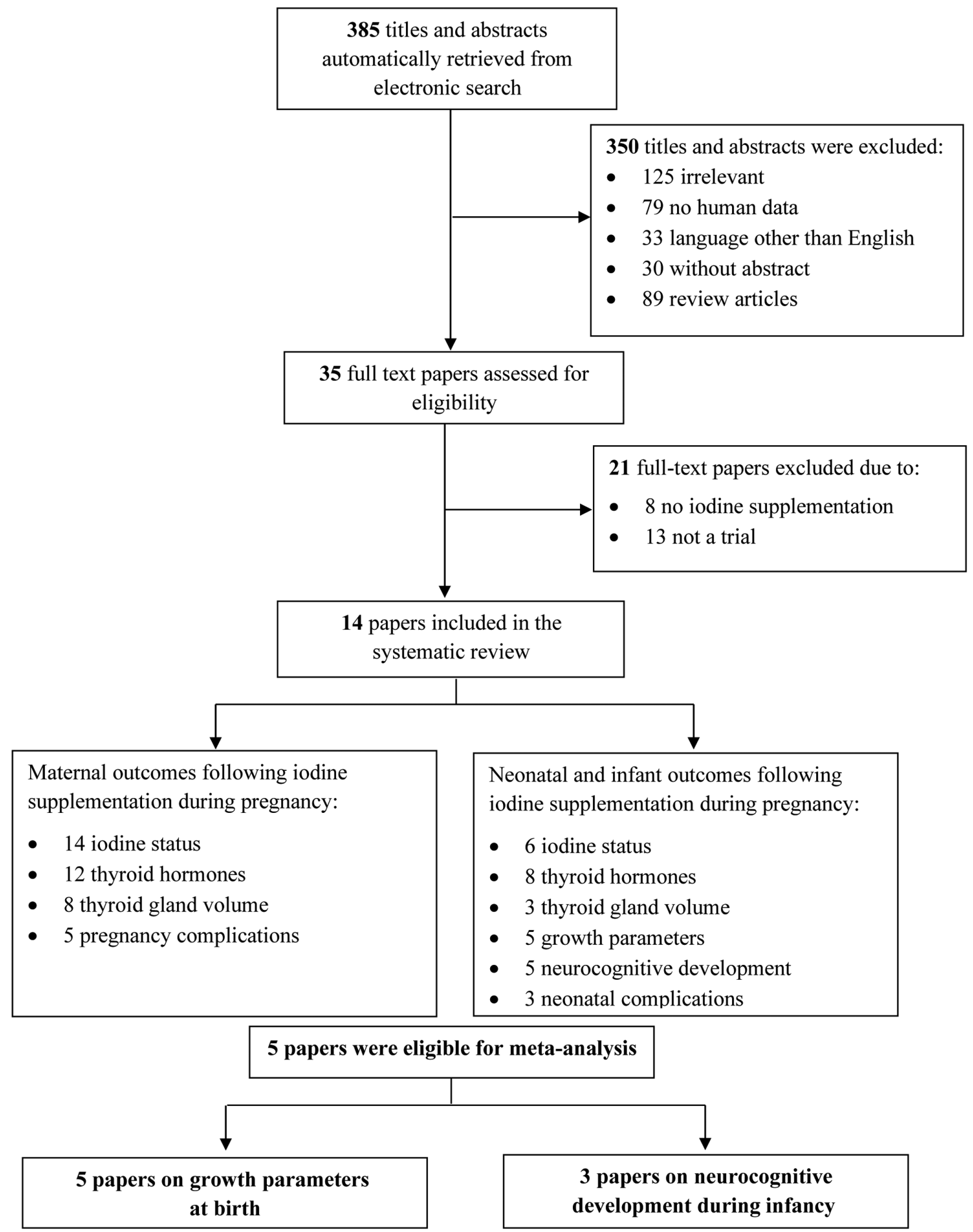

Figure 1

Flow chart of trials selection for the present systematic review and meta-analysis. 

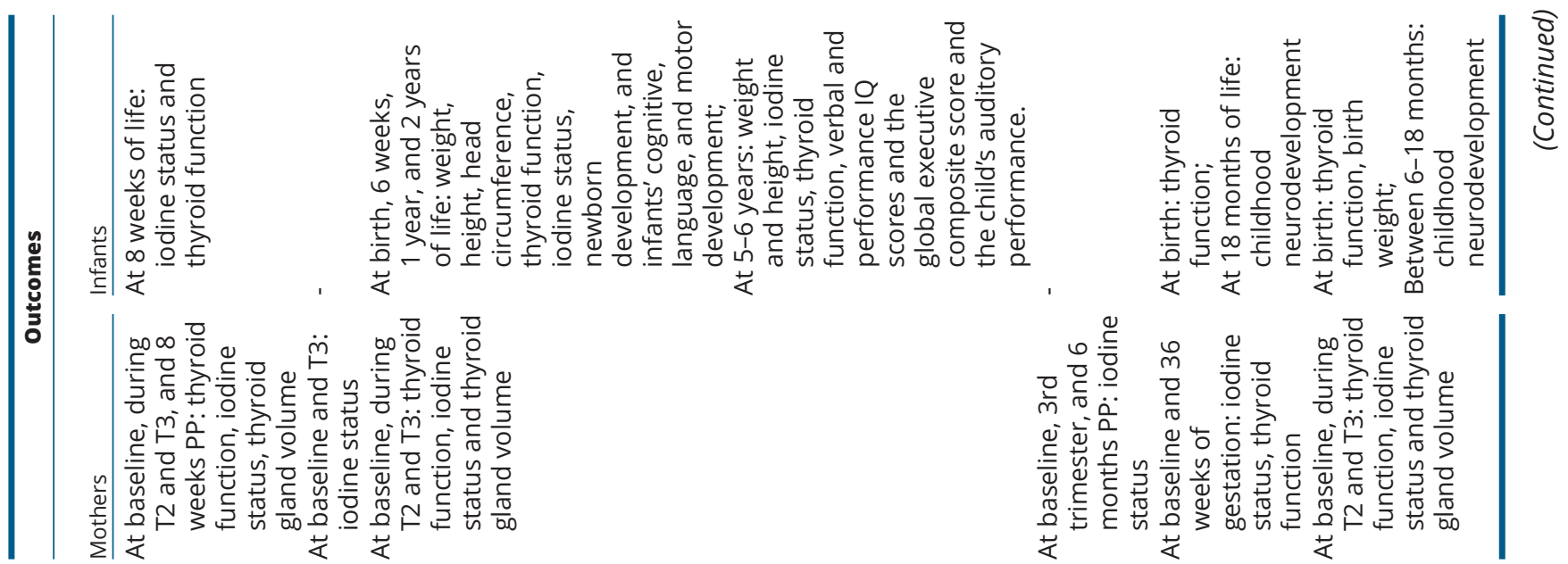

$$
\text { 峁 }
$$

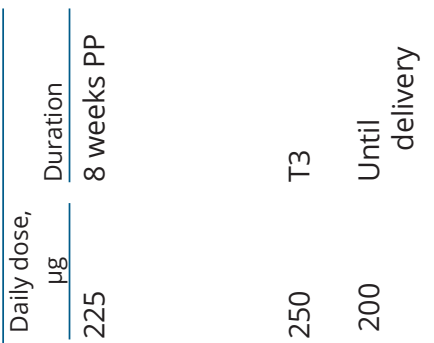

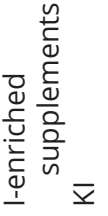

유 유
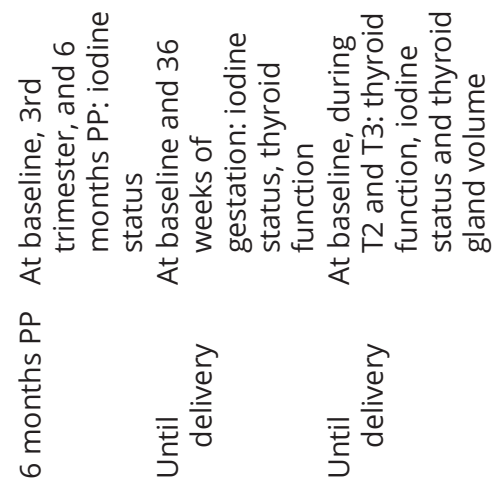

0

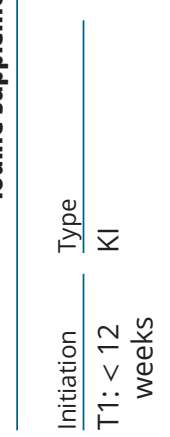

ก

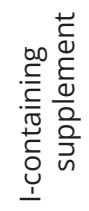

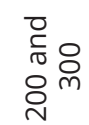

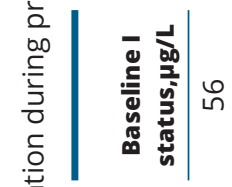

$\stackrel{n}{m} \stackrel{\bar{m}}{\leftarrow}$

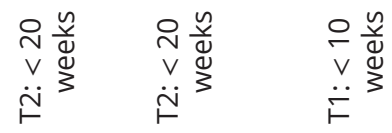

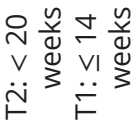

$\stackrel{\infty}{+}$

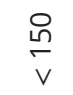

$\stackrel{\circ}{\circ}$

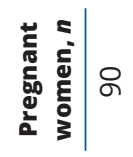

$\stackrel{\sim}{m} \stackrel{\infty}{\infty}$

$\stackrel{\stackrel{n}{ }}{\check{2}}$

ำ

$\stackrel{\infty}{\bullet}$

总

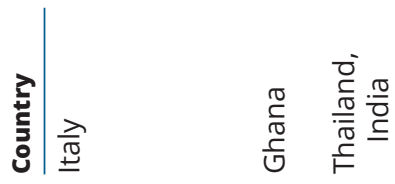

๖

$\longleftarrow$

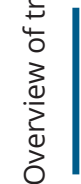

$\underset{\nwarrow}{\longleftarrow}$

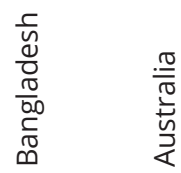

$\frac{\sqrt{\frac{5}{\pi}}}{\stackrel{0}{2}}$

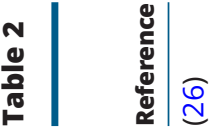

$\overline{\bar{d}} \bar{d}$

$\widehat{\widetilde{M}}$

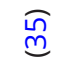

$\stackrel{\text { m}}{m}$ 

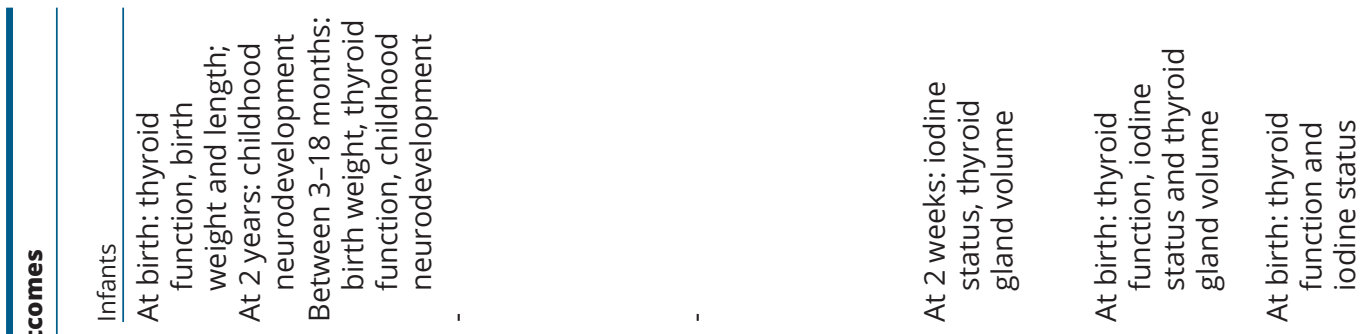

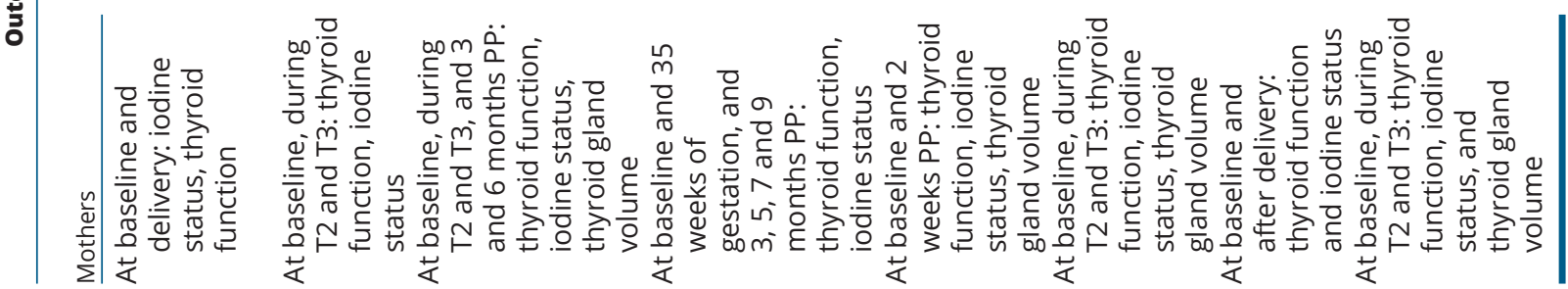
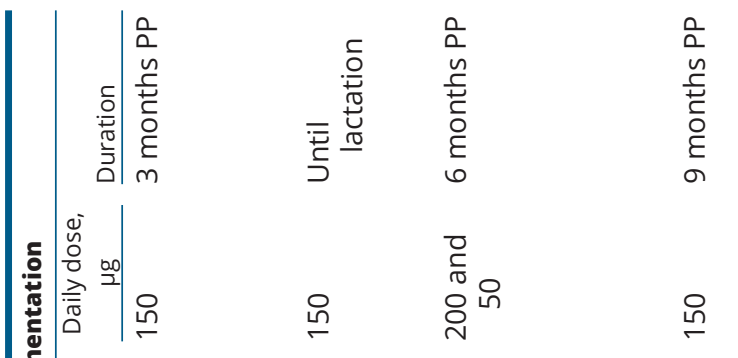

욤

\&

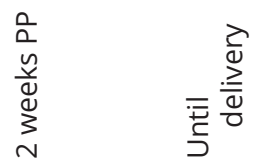

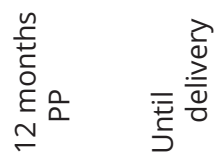
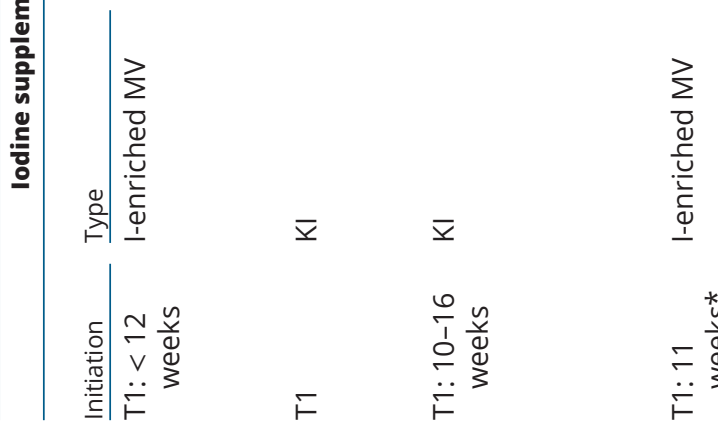

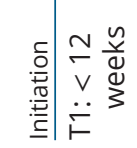

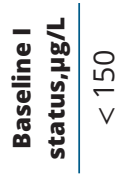

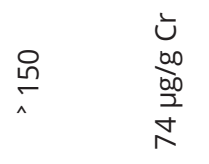

$\frac{8}{\mathrm{v}}$

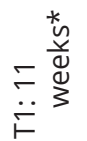

꼴

$\stackrel{8}{\circ}$

옳

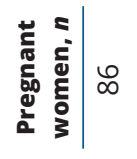

$\stackrel{\circ}{2} \infty$

$\ddot{\bullet}$

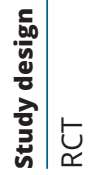

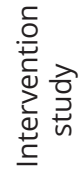

$\underset{\longleftarrow}{\longleftarrow}$

$\underset{ષ}{\longleftarrow}$

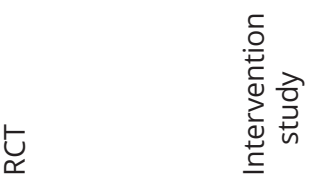

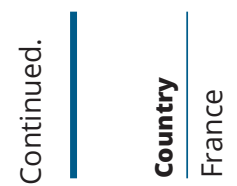

든

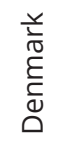

ษ

$\sqrt{\frac{+}{+}} \quad \frac{\overrightarrow{+}}{\frac{+}{+}}$

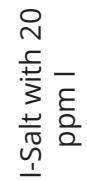

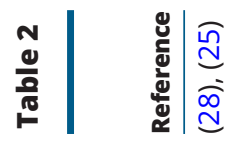

舀

ọ

ฮู

ฮิ

㐫

్ㅗ

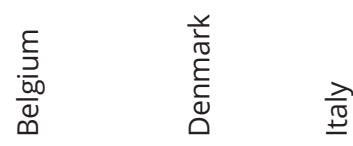


UIC varied from 36 to $137 \mu \mathrm{g} / \mathrm{L}$ before the intervention. Based on the median UIC of $150 \mu \mathrm{g} / \mathrm{L}$ as the indicator of iodine status during pregnancy, all pregnant women were iodine -deficient. In most trials, iodine supplementation was administered during the first trimester of pregnancy as potassium iodide $(\mathrm{KI})$ preparations $(n=9)(22,24$, $26,27,29,31,33,34,35)$, iodine-containing vitamin preparations $(n=4)(21,23,28,30)$, or iodized salt $(n=1)$ (32). Moreand thyroid gland size, respectied from 50 to $300 \mu \mathrm{g}$.

Fourteen trials investigated the effects of iodine supplementation on maternal iodine status $(21,22$, $23,24,26,27,28,29,30,31,32,33,34,35) ; 12$ on different thyroid parameters, such as thyroid-stimulating hormone (TSH), thyroxine (T4), free thyroxine (FT4), triiodothyronine (T3), free triiodothyronine (FT3), thyroglobulin ( $\mathrm{Tg})$, and thyroid peroxidase antibody (TPO-Ab) $(22,24,26,27,28,29,30,31,32,33,34,35)$; and eight on the size of the thyroid gland during pregnancy $(22,24,26,27,29,31,32,33)$. Of these, six $(22,26,27,29$, $31,34)$, eight $(22,26,27,28,31,33,34,35)$, and three $(27$, $31,33)$ trials also collected data on neonatal iodine status, thyroid hormones (mainly TSH), and thyroid gland size, respectively (Table 3 ). In five trials, the effects of iodine supplementation on birth growth parameters $(22,28,33$, $34,35)$ (Table 4) and child neurocognitive development $(22,25,33,34,35)$ (Table 5) were investigated, and five $(22,28,33,34,35)$ and three $(22,25,35)$ trials were eligible for inclusion in the meta-analysis, respectively. Five trials reported the frequency of the clinical complications in pregnant women and their neonates following iodine supplementation during pregnancy $(22,26,34,35)$ (Table 6). The scoring of the risk of bias assessment is shown in Table 7 . The overall quality of the included studies was poor, with only 34 of 98 items judged to be at low risk of bias. Risk of bias was highest for the blinding ( 9 trials) and the incomplete outcome data (5 trials) domains.

\section{Maternal iodine status and different thyroid parameters following iodine supplementation during pregnancy}

As indicated in Table 3, in most included trials, maternal UIC consistently increased following iodine supplementation during pregnancy, except for a trial conducted in Bangladesh that reported daily consumption of lipid-based nutrient supplement (containing $250 \mu \mathrm{g}$ iodine) did not result in improved UIC (23). However, findings of the effects of iodine supplementation on TSH were inconsistent. Of the 12 trials, 4 reported a rise in
TSH levels within the normal range during pregnancy in the control groups, whereas 5 trials found no change in women who received iodine supplements. Only in two trials, TSH concentration tended to be lower in the iodine supplement group, than in the control group. Most trials reported no significant change in maternal T4, FT4, T3, or FT3 concentrations between the iodine-supplemented and control groups. Of the ten trials that collected information on Tg during pregnancy, six reported a lower concentration of $\mathrm{Tg}$ in women taking iodine supplements, than in those of the control group. Two trials collected data on the marker of thyroid autoimmunity during pregnancy; none of these showed statistically significant differences in TPO-Ab positivity between intervention and control groups. Among the eight trials that investigated the effects of iodine supplementation on thyroid gland size during pregnancy, four found no significant difference between women who received iodized salt only and who received 200 or $300 \mu \mathrm{g}$ KI daily or between those who received 50 vs $300 \mu \mathrm{g}$ of iodine daily. Out of the eight trials, four reported that the thyroid gland size in women in the iodine-supplemented group was smaller than that of women in the control group.

\section{Neonatal and infant outcomes following iodine supplementation during pregnancy}

lodine status and thyroid parameters

The effects of maternal iodine supplementation on neonatal UIC and thyroid parameters are shown in Table 3. In nearly all trials (5 of 6 ), significant improvement in the UIC of infants whose mothers were supplemented with iodine during pregnancy was observed. However, most trials (7 of 8 ) did not find any significant difference in neonatal TSH between the intervention and control groups. None of the trials reported any effects of iodine supplementation on neonatal T4, FT4, T3, or FT3 concentrations. Of the four trials that assessed $\mathrm{Tg}$ in the cord blood sample of newborns, two found a significant increase of $\mathrm{Tg}$ concentration in neonates born to mothers receiving placebo or who did not take iodine supplements. In two of three trials that reported this outcome, infants of supplemented mothers had a smaller thyroid gland size than infants of non-supplemented mothers.

\section{Growth parameters at birth}

Five trials investigated the impact of maternal iodine supplementation on the growth parameters of neonates 


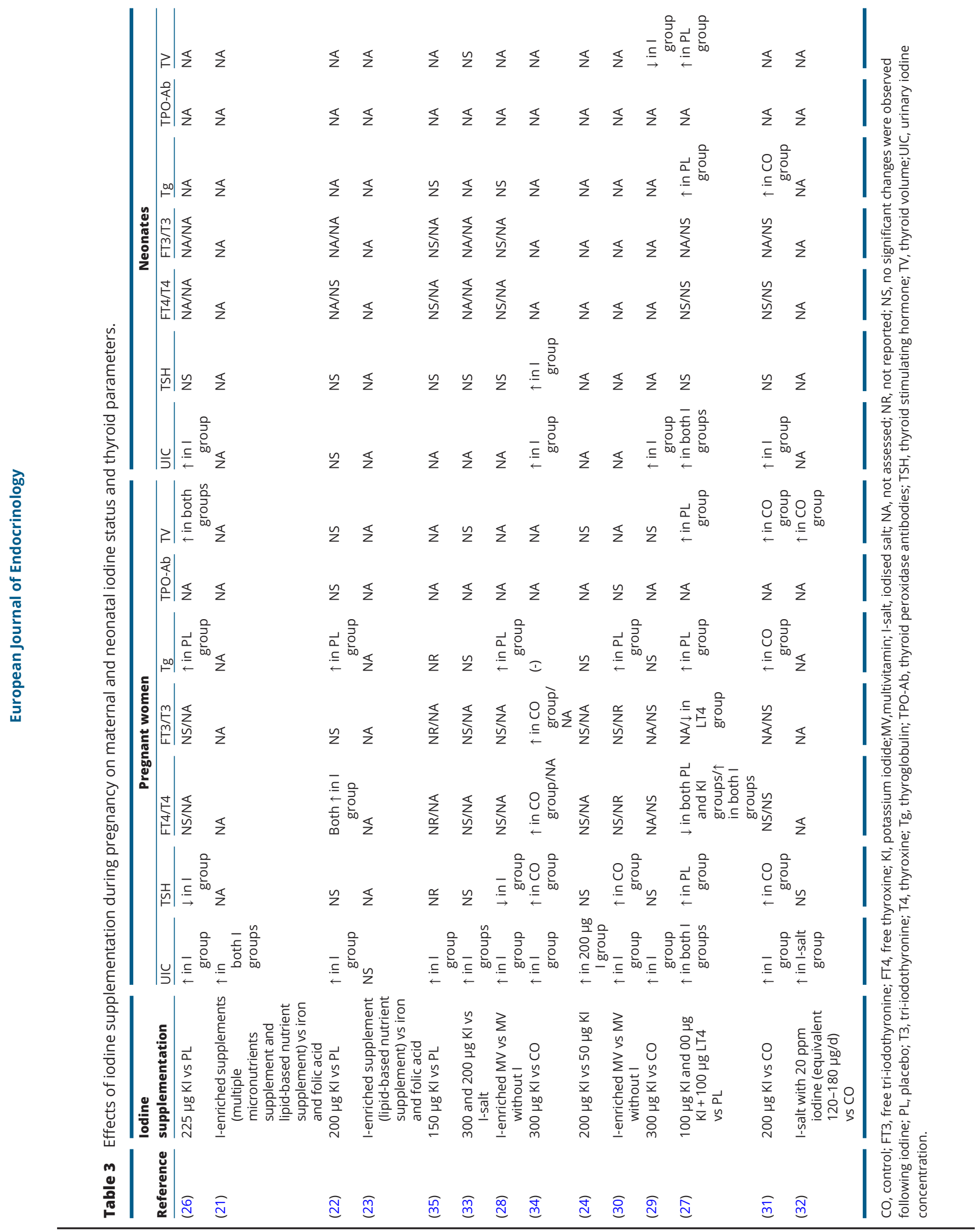


Table 4 Effects of iodine supplementation during pregnancy on neonatal growth parameters at birth.

\begin{tabular}{|c|c|c|c|c|c|}
\hline \multirow[b]{2}{*}{ Reference } & \multirow[b]{2}{*}{ lodine supplementation } & \multicolumn{4}{|c|}{ Anthropometric measures at birth } \\
\hline & & Weight & Length & $\mathrm{HC}$ & Other \\
\hline$(22)$ & $200 \mu \mathrm{g} \mathrm{KI}$ vs PL & ND & ND & ND & Length for age z-score: ND \\
\hline (35) & $150 \mu \mathrm{g} \mathrm{KI}$ vs PL & ND & ND & ND & Placenta weight: ND \\
\hline (33) & 300 and $200 \mu g$ KI vs I-salt & ND & NA & NA & NA \\
\hline$(28)$ & I- enriched MV vs MV without I & $\downarrow$ in I group & $\downarrow$ in I group & NA & NA \\
\hline$(34)$ & $300 \mu \mathrm{g} \mathrm{KI}$ vs CO & ND & NA & NA & NA \\
\hline
\end{tabular}

CO,control; I-salt, iodised salt; KI, potassium iodide; MV, multivitamin; NA, not assessed; ND, no differences between groups; PL, placebo.

(Table 4). Among them, the study conducted by Hiéronimus et al. (28) showed a lower birth weight and shorter length in newborns whose mothers took iodine supplements during pregnancy. None of the trials reported a positive impact of iodine supplementation on neonatal anthropometric indices, including birth weight, length, head circumference, or placental weight. The pooled-SMDs and 95\% CIs for birth weight, length, and head circumference between the iodine-supplemented and control groups are shown in Fig. 2A, B and C. As there was no significant heterogeneity among the included studies in terms of birth weight $(P=0.062)$ or length $(P=0.116)$, the fixed-effect model was used. There were no significant differences in birth weight $(-0.11$ (95\% CI: -0.23 to 0.01$)$ ), length ( -0.06 (95\% CI: -0.21 to 0.09$)$ ), or head circumference $(0.26$ (95\% CI: -0.35 to 0.88$)$ ) of infants between iodine-supplemented and control groups.

\section{Neurocognitive development}

Table 5 shows neurocognitive development in infants and children following iodine supplementation during pregnancy. In three of five trials, infants aged 12-24 months were examined for the three key developmental functions using the Bayley Scales of Infant Development Third edition tool. The pooled-SMDs and 95\% CIs for cognition, language, and motor functions in infants whose mothers received iodine supplementation during pregnancy, compared with those whose mothers did not receive supplementation are provided in Fig. 3A, B and $C$. There was no significant heterogeneity among included studies in terms of cognitive $(P=0.285)$ or motor $(P=0.751)$ functions; therefore, the fixed-effect model was used. No differences were observed in cognitive (0.07 (95\% CI: -0.07 to 0.20)), language (0.06 (95\% CI: -0.22 to 0.35$))$, or motor $(0.07$ (95\% CI: -0.06 to 0.21$)$ )

Table 5 Effects of iodine supplementation during pregnancy on neurocognitive development of infants and children.

\begin{tabular}{|c|c|c|c|c|c|c|}
\hline \multirow[b]{2}{*}{ Reference } & \multirow[b]{2}{*}{ lodine supplementation } & \multirow[b]{2}{*}{ Infants, $n$} & \multirow[b]{2}{*}{ Age } & \multicolumn{2}{|c|}{ Neurocognitive development } & \multirow[b]{2}{*}{ Main effect(s) } \\
\hline & & & & Scale & Outcomes & \\
\hline \multirow{4}{*}{$(22)$} & $200 \mu \mathrm{g} \mathrm{KI}$ vs PL & 832 & 6 week & NBAS & Newborn development & NS \\
\hline & & 399 & 1 year & BSID-III & $\begin{array}{l}\text { Cognitive, language, and } \\
\text { motor development }\end{array}$ & $\begin{array}{l}\text { NS, except } \downarrow \text { expressive } \\
\text { language score at }\end{array}$ \\
\hline & & 430 & 2 years & BSID-III & $\begin{array}{l}\text { Cognitive, language, and } \\
\text { motor development }\end{array}$ & 1 year in iodine group \\
\hline & & 330 & $5-6$ years & WPPSI-III & $\begin{array}{l}\text { Verbal and performance IQ, } \\
\text { performance speed } \\
\text { quotient, and full scale IQ }\end{array}$ & NS \\
\hline$(25)$ & $\begin{array}{l}\text { I-enriched MV vs MV } \\
\text { without I }\end{array}$ & 44 & 2 years & BSID-III & $\begin{array}{l}\text { Cognitive, language, and } \\
\text { motor development }\end{array}$ & NS \\
\hline$(35)$ & $150 \mu g \mathrm{KI}$ vs PL & 53 & 18 months & BSID-III & $\begin{array}{l}\text { Cognitive, language, and } \\
\text { motor development }\end{array}$ & NS \\
\hline (33) & $\begin{array}{l}300 \text { and } 200 \mu g \text { KI vs } \\
\text { I-salt }\end{array}$ & 111 & 6-18 months & BSID-III & $\begin{array}{l}\text { Mental and psychomotor } \\
\text { development indices, and } \\
\text { behavior rating scale }\end{array}$ & NS \\
\hline$(34)$ & $300 \mu g \mathrm{KI}$ vs CO & 194 & 3-18 months & BSID-I & $\begin{array}{l}\text { Mental and psychomotor } \\
\text { development indices, and } \\
\text { behavior rating scale }\end{array}$ & $\begin{array}{l}\uparrow \text { scores on psychomotor } \\
\text { development index and } \\
\text { behavior rating scale in } \\
\text { iodine group }\end{array}$ \\
\hline
\end{tabular}

BSID, Bayley scales of infant development; CO, control; IQ, intelligence quotient; I-salt, iodised salt; KI, potassium iodide; MV, multivitamin; NBAS, neonatal behavioral assessment scale; NS, no significant improvements were observed following iodine supplementation. PL, placebo, WPPSI, Wechsler preschool and primary scale of intelligence. 


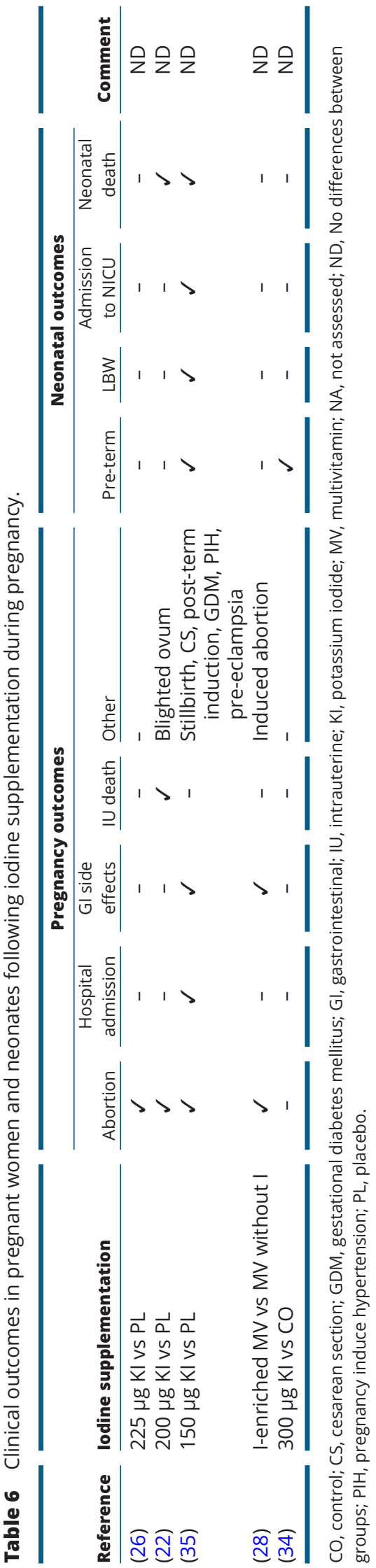

development in infants of both groups. Only one trial conducted by Gowachirapant et al. (22) investigated the effect of iodine supplementation in pregnant women on the neurodevelopment of children aged 5-6 years using the Wechsler Preschool and Primary Scale of Intelligence Third Edition tool. The authors reported that children of mothers who received iodine had similar scores in verbal and performance IQ to those that whose mothers did not receive iodine.

\section{Maternal and neonatal clinical complications following iodine supplementation during pregnancy}

As presented in Table 6, of the 14 trials included in the systematic review, 5 reported clinical complications, such as gastrointestinal side effects, gestational diabetes mellitus, pregnancy-induced hypertension, and preeclampsia, increased hospital admission, abortion, stillbirth, intrauterine death, cesarean section, and postterm induction following the iodine supplementation in pregnant women. Complications observed in neonates included premature, low birth weight, admission to neonatal intensive care unit, and death. Notably, the frequency of the aforementioned outcomes in pregnant women and neonates did not differ between the two groups for various doses of iodine supplementation.

\section{Discussion}

The present systematic review, which comprehensively assessed the potential effects of iodine supplementation during pregnancy indicated improvement of iodine status in pregnant women and neonates in most of the trials. Although the findings of different thyroid parameters are inconclusive, more consistent evidence reported that iodine supplementation could prevent the increase in Tg concentration during pregnancy. A meta-analysis of available studies showed that iodine supplementation had no beneficial effects on weight, length, or head circumference at birth, and on cognitive, language, or motor development during the first 2 years of life.

Few studies have investigated the benefits of iodine supplementation before pregnancy. In Spain, pregnant women who consumed iodized salt for at least 1 year before pregnancy had significantly higher urinary iodine levels and smaller thyroid gland size in the 3rd trimester than women who received 200 or $300 \mu$ g iodine during pregnancy (33). Similarly, in Australia, urinary iodine 
Table 7 Risk of bias assessment for the included trials in the systematic review.

\begin{tabular}{|c|c|c|c|}
\hline \multirow[b]{2}{*}{ Reference } & \multicolumn{2}{|c|}{ Selection bias } & \multirow[b]{2}{*}{$\begin{array}{c}\text { Performance } \\
\text { bias }^{1}\end{array}$} \\
\hline & $\begin{array}{c}\text { Random sequence } \\
\text { generation }\end{array}$ & $\begin{array}{c}\text { Allocation } \\
\text { concealment }\end{array}$ & \\
\hline (26) & L & L & $\mathrm{L}$ \\
\hline (21) & $\mathrm{L}$ & L & $\mathrm{H}$ \\
\hline$(22)$ & L & L & $\mathrm{L}$ \\
\hline (23) & $U$ & L & $\mathrm{H}$ \\
\hline (35) & L & L & $\mathrm{H}$ \\
\hline (33) & L & $U$ & $\mathrm{H}$ \\
\hline (28) & L & $\mathrm{H}$ & $\mathrm{H}$ \\
\hline (34) & $\mathrm{H}$ & U & $\mathrm{H}$ \\
\hline (24) & $U$ & $U$ & $\mathrm{H}$ \\
\hline (30) & U & U & $\mathrm{L}$ \\
\hline (29) & $\mathrm{H}$ & $\mathrm{H}$ & $\cup$ \\
\hline (27) & $U$ & $U$ & $\mathrm{~L}$ \\
\hline (31) & $\cup$ & $U$ & $\mathrm{H}$ \\
\hline (32) & $U$ & $U$ & $\mathrm{H}$ \\
\hline
\end{tabular}

\begin{tabular}{c}
$\begin{array}{c}\text { Detection } \\
\text { bias }^{2}\end{array}$ \\
\hline $\mathrm{L}$ \\
$\mathrm{L}$ \\
$\mathrm{L}$ \\
$\mathrm{L}$ \\
$\mathrm{U}$ \\
$\mathrm{L}$ \\
$\mathrm{U}$ \\
$\mathrm{L}$ \\
$\mathrm{L}$ \\
$\mathrm{U}$ \\
$\mathrm{L}$ \\
$\mathrm{L}$ \\
$\mathrm{L}$ \\
$\mathrm{L}$
\end{tabular}

\begin{tabular}{c}
\hline $\begin{array}{c}\text { Attrition } \\
\text { bias }^{3}\end{array}$ \\
\hline$H$ \\
$H$ \\
$L$ \\
$H$ \\
$H$ \\
$U$ \\
$H$ \\
$U$ \\
$U$ \\
$U$ \\
$U$ \\
$U$ \\
$L$ \\
$L$
\end{tabular}

\begin{tabular}{c}
$\begin{array}{c}\text { Reporting } \\
\text { bias }^{4}\end{array}$ \\
\hline$L$ \\
$H$ \\
$U$ \\
$L$ \\
$L$ \\
$U$ \\
$L$ \\
$U$ \\
$U$ \\
$U$ \\
$U$ \\
$U$ \\
$U$ \\
$U$
\end{tabular}

\begin{tabular}{|c|c|}
\hline $\begin{array}{l}\text { Other } \\
\text { bias }^{5}\end{array}$ & Total $^{6}$ \\
\hline$U$ & $5 / 7$ \\
\hline$U$ & $3 / 7$ \\
\hline$U$ & $5 / 7$ \\
\hline$U$ & $3 / 7$ \\
\hline$U$ & $3 / 7$ \\
\hline $\mathrm{H}$ & $2 / 7$ \\
\hline$L$ & $3 / 7$ \\
\hline U & $1 / 7$ \\
\hline $\mathrm{H}$ & $1 / 7$ \\
\hline $\mathrm{H}$ & $1 / 7$ \\
\hline$U$ & $1 / 7$ \\
\hline$U$ & $2 / 7$ \\
\hline$U$ & $2 / 7$ \\
\hline U & $2 / 7$ \\
\hline
\end{tabular}

${ }^{1}$ Blinding of participants and personnel; ${ }^{2}$ Blinding of outcome assessors; ${ }^{3}$ ncomplete outcome data; ${ }^{4}$ Selective reporting; ${ }^{5}$ Anything else, ideally pre-specified; ${ }^{6}$ Low on risk of bias.

$H$, high risk of bias; L, low risk of bias; $U$, unclear risk of bias.

levels in women who started iodine supplementation before conception did not decline throughout gestation period and were within the optimal range, compared with those who started supplementations following pregnancy confirmation (37). These findings suggest that iodine supplementation during preconception provides satisfactory iodine status and improves thyroid storage during the pregnancy, with the need for thyroid hormones increasing substantially. In our systematic review, no significant changes were observed in maternal and neonatal thyroid parameters (i.e. T4, FT4, T3, or FT3) following iodine supplementation during pregnancy. However, there was more consistent evidence regarding higher Tg concentration in non-supplemented women, which reflected thyroid stress to produce adequate thyroid hormone in response to limited iodine supply $(22,26$, $27,28,30,31)$. These observations agree with those of a previous meta-analysis, which found no difference in the likelihood of maternal or neonatal thyroid dysfunction between pregnant women who received iodine supplementation and those in the control group (38).

There is a large body of evidence indicating that severe iodine deficiency during pregnancy may lead to adverse effects on birth weight or fetal growth, and iodine repletion through the administration of iodized oil or salt significantly improves birth outcomes (39). However, there is no definitive evidence that iodine repletion in pregnant women improves growth outcomes. In a meta-analysis performed by Farebrother et al. iodine supplementation to treat severe iodine deficiency in pregnant women, on average, resulted in a $200 \mathrm{~g}$ increase in weight and 0.4 $\mathrm{cm}$ greater head circumference at birth in infants born to supplemented women than those born to women in the control group, but no effect was found in mildly to moderately iodine-deficient pregnant women (40). In our meta-analysis, regardless of the degree of maternal iodine deficiency, there were no differences in birth weight, length, or head circumference between infants born to women who received iodine supplementation during pregnancy and those born to non-supplemented women. In line with the findings of the current study, in a recent systematic review and meta-analysis conducted by Nazeri et al., anthropometric measurements at birth were not associated with maternal iodine status during pregnancy (41). However, regarding the lack of trials on this issue, the interpretation of our results may be challenging.

Data on the benefits of iodine supplementation during pregnancy for child neurocognitive development are still inconclusive. For instance, a study conducted by Velasco et al. showed a positive effect on psychomotor scores that was observed in children of mothers who received $300 \mu \mathrm{g}$ iodine starting 10 weeks before the gestation when compared with the control group (34). Gowachirapant et al. did not report any beneficial effects but reported some indications of negative effects on the neurodevelopment of children following iodine supplementation 14 weeks before the gestation (22). This discrepancy may be explained by the fact that the effect of iodine on the neurocognitive development of children varies at different stages of pregnancy. In a recent meta-analysis on individual-participants data from three 
A

First author (year)

Velasco I et al. (2009)

Hiéronimus S et al. (2012)

Santiago P et al. (2013)

Santiago P et al. (2013)

Zhou SJ et al. (2015)

Gowachirapant S et al. (2017)

Overall (I-squared $=52.4 \%, P=0.062)$

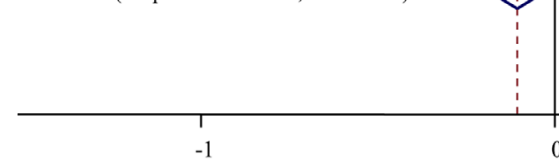

Iodine group Control group

SMD (95\% CI) N, mean (SD) N, mean (SD) Weight (\%)

$0.21(-0.09,0.52) \quad 133,3340(360) \quad 61,3250(540) \quad 15.90$

$-0.44(-0.88,0.00) \quad 32,3160(402) \quad 54,3420(680) \quad 7.51$

$-0.40(-0.82,0.02) \quad 55,3170(510) \quad 38,3360(420) \quad 8.42$

$-0.32(-0.77,0.14) \quad 38,3160(790) \quad 38,3360(420) \quad 7.17$

$0.20(-0.31,0.72) \quad 29,3325(475) \quad 29,3204(689) \quad 5.51$

$-0.11(-0.28,0.05) \quad 286,2980(440) \quad 296,3030(440) 55.49$

$\begin{array}{llll}-0.11(-0.23,0.01) & 573 & 516 & 100.00\end{array}$

B

\begin{tabular}{|c|c|c|c|c|}
\hline First author (year) & SMD $(95 \%$ CI $)$ & $\begin{array}{l}\text { Iodine group } \\
\mathrm{N} \text {, mean (SD) }\end{array}$ & $\begin{array}{l}\text { Control group } \\
\mathrm{N} \text {, mean (SD) }\end{array}$ & Weight (\%) \\
\hline Hiéronimus S et $a l . \overline{(2012)}$ & $-0.50(-0.94,-0.06)$ & $32,48(2)$ & $54,49(2)$ & 11.64 \\
\hline Zhou SJ et al. (2015) & $0.00(-0.51,0.51)$ & $29,49(2)$ & $29,49(3)$ & 8.65 \\
\hline Gowachirapant S et al. (2017) & $0.00(-0.17,0.17)$ & $261,49(2)$ & $274,49(2)$ & 79.72 \\
\hline Overall $($ I-squared $=53.6 \%, P=0.116)$ & $-0.06(-0.21,0.09)$ & 322 & 357 & 100.00 \\
\hline-1 & 1 & & & \\
\hline
\end{tabular}

C

First author (year)

Iodine group Control group SMD (95\% CI) N, mean (SD) N, mean (SD) Weight (\%)

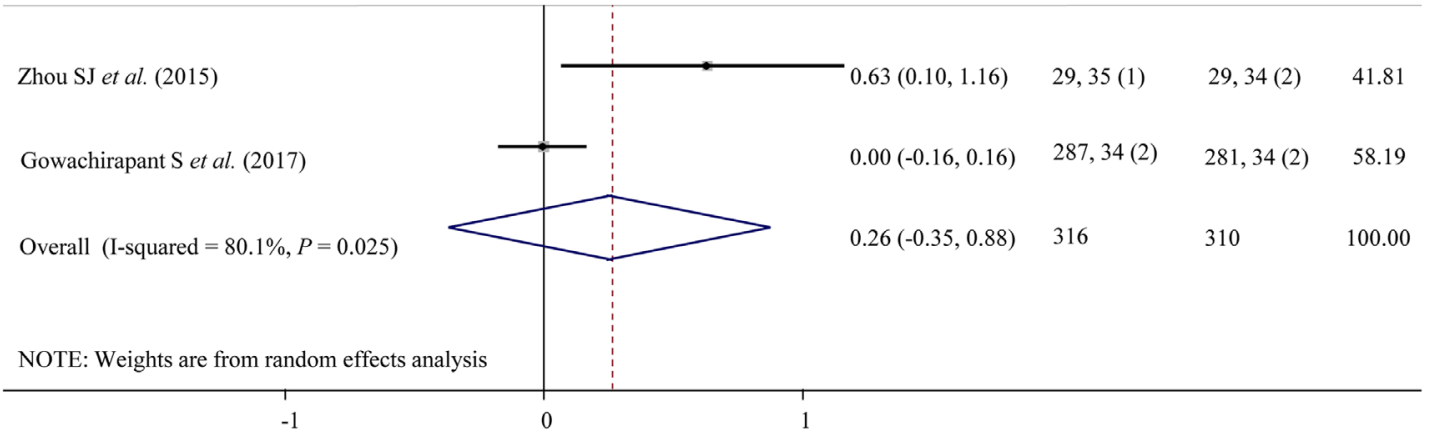

\section{Figure 2}

Standardized mean difference and 95\% confidence interval and the pooled estimates for weight (A), length (B), and head circumference $(C)$ at birth in the iodine-supplemented group compared with the control group. Open diamonds represent the pooled estimates for anthropometric measures at birth. The solid diamonds represent the point estimate of each study (horizontal lines represent $95 \% \mathrm{Cls}$ ) and the size of squares is proportional to the percentage weight of each study. The $\mathrm{I}^{2}$ values refer to the statistical heterogeneity of combined studies. SMD, standardized mean difference. A full color version of this figure is available at https://doi.org/10.1530/EJE-20-0927. 
A

First author (year)

Brucker-Davis F et al. (2015)

Zhou SJ et al. (2015)

Gowachirapant S et al. (2017)

Gowachirapant S et al. (2017)

Overall (I-squared $=20.9 \%, P=0.285$ )

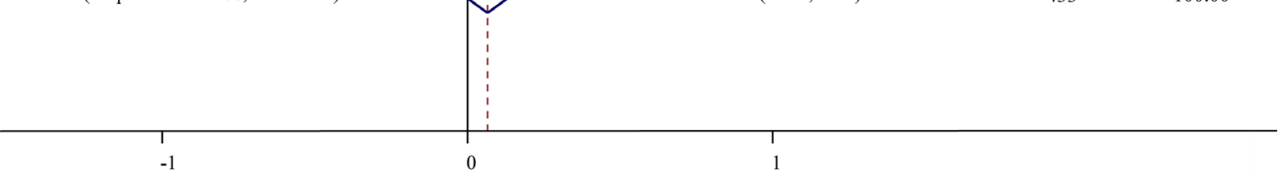

B

First author (year)
Iodine group Control group

SMD (95\% CI) N, mean (SD) N, mean (SD) Weight (\%)

$0.00(-0.60,0.60) \quad 19,110(14) \quad 25,110(14) \quad 4.99$

$-0.29(-0.83,0.25) \quad 27,99(12) \quad 26,102(8) \quad 6.06$

$0.20(-0.01,0.41) \quad 181,45(5) \quad 180,44(5) \quad 41.54$

$0.00(-0.19,0.19) \quad 208,63(5) \quad 202,63(6) \quad 47.41$

$0.07(-0.07,0.20) \quad 435 \quad 433 \quad 100.00$

Iodine group Control group

SMD (95\% CI) N, mean (SD) N, mean (SD) Weight (\%)

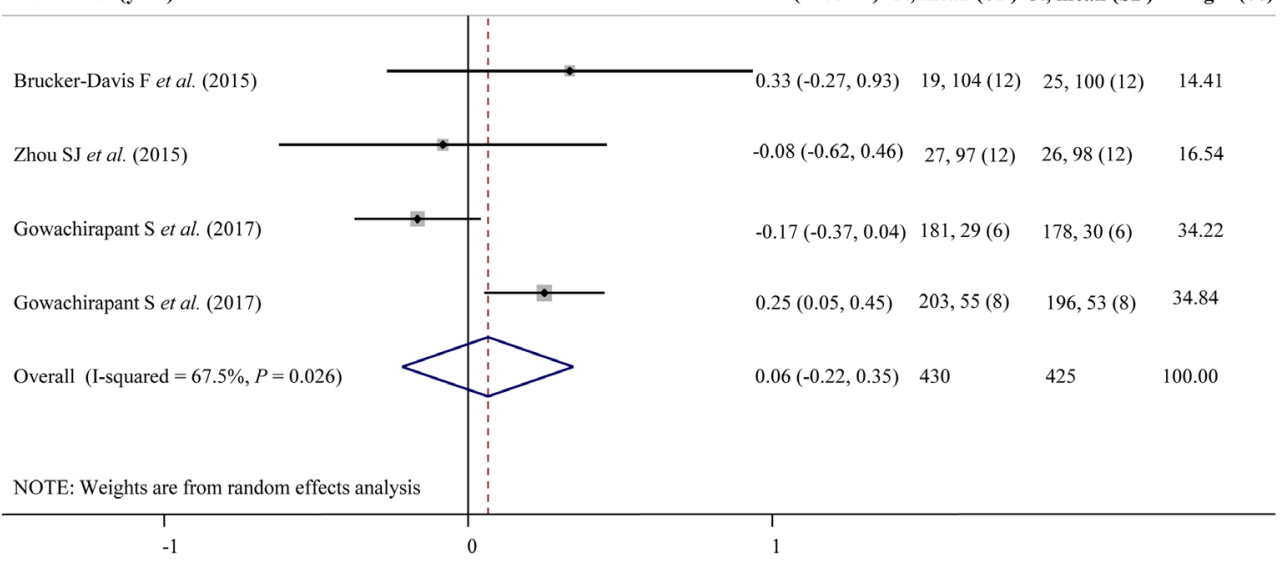

Cirst author (year)

Iodine group Control group

SMD $(95 \%$ CI)

, mean (SD) N, mean (SD) Weight (\%)

Brucker-Davis F et al. (2015)

Zhou SJ et al. (2015)

Gowachirapant S et al. (2017)

Gowachirapant S et al. (2017)

Overall (I-squared $=0.0 \%, P=0.751$ )

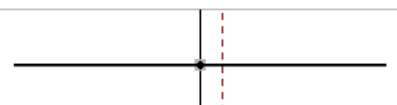

$0.00(-0.60,0.60)$

$19,110(7)$

$25,110(10) \quad 5.06$

$0.19(-0.35,0.73)$

27, $94(11)$

$26,92(10) \quad 6.18$

$0.14(-0.06,0.35)$

$180,74(7) \quad 178,73(7) \quad 41.81$

$0.00(-0.20,0.20) \quad 202,96(8) \quad 199,96(7) \quad 46.95$

$\begin{array}{llll}0.07(-0.06,0.21) & 428 & 428 & 100.00\end{array}$

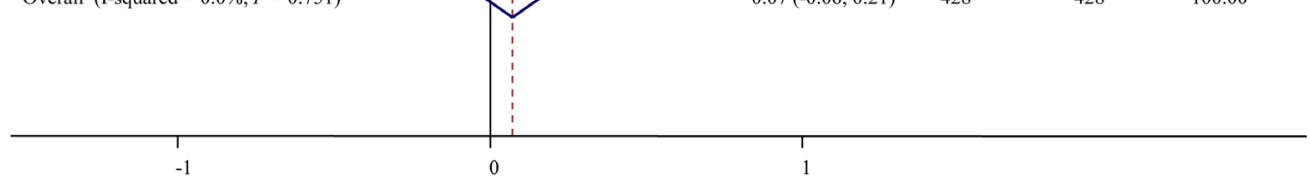

\section{Figure 3}

Standardized mean difference and 95\% confidence interval and the pooled estimates for cognitive (A), language (B), and motor (C) development during infancy in the iodine-supplemented group compared with the control group. Open diamonds represent the pooled estimates for neurodevelopment outcomes during infancy. The solid diamonds represent the point estimate of each study (horizontal lines represent $95 \% \mathrm{Cls}$ ) and the size of squares is proportional to the percentage weight of each study. The $\mathrm{I}^{2}$ values refer to the statistical heterogeneity of combined studies. SMD, standardized mean difference. A full color version of this figure is available at https://doi.org/10.1530/EJE-20-0927. 
cohorts, lower maternal iodine status during pregnancy was associated with lower child verbal IQ up until the start of the 2nd trimester (42). However, in this meta-analysis, iodine supplementation of mildly iodine-deficient pregnant women had no clear benefit on neurocognitive outcomes during infancy, which may be attributed to the physiological adaption of pregnant women to low intake of iodine to maintain fetal thyroid hormones at a normal level for in utero development.

The main strengths of this study were considering a broad range of outcomes of pregnant women and their neonates, and conducting meta-analysis on birth growth status and neurocognitive development in infants. However, given the limited number of available studies, the research team could not conduct a subgroup-analysis based on the degree of iodine deficiency at baseline. This limitation also made us unable to perform statistical tests for publication bias because if less than ten studies are included, the power of the test is low.

\section{Conclusion}

A systematic review of trials conducted over the past 3 decades indicated that iodine supplementation during pregnancy could improve iodine status in pregnant women and their neonates; however, the impact of iodine administration on maternal and neonatal thyroid parameters is not clear. According to our metaanalysis, there was no evidence of improved growth or neurodevelopmental outcomes in infants of iodinesupplemented mothers. The lack of beneficial effects of iodine supplements can be attributed to many factors: i) late administration of iodine supplementation, given the increasing evidence on the importance of preconception supplementation, (ii) the physiologic response to iodine repletion, which may be different depending upon the degree of iodine deficiency before treatment, and (iii) as evidence resulted from trials is not sufficient, drawing definitive conclusions may be difficult, particularly when considering trials on infant/child growth status and neurocognitive development. Well-designed randomized controlled trials with special emphasis on the aforementioned points are warranted. Also, more data are needed to determine optimal and safe upper limits of iodine supplementation in pregnant women and assess the potential risks of chronic high iodine intake during pregnancy.

\section{Supplementary materials}

This is linked to the online version of the paper at https://doi.org/10.1530/ EJE-20-0927.

\section{Declaration of interest}

The authors declare that there is no conflict of interest that could be perceived as prejudicing the impartiality of this study.

\section{Funding}

This study was supported by financial grants from Tehran University of Medical Sciences, Tehran, Iran (grant number 99-1-152-48028)

\section{Author contribution statement}

P N contributed to literature search, data collection, analysis, and interpretation, writing, reading, and final approval of the manuscript. M S contributed to literature search, data collection and interpretation, writing, reading, and final approval of the manuscript. F A contributed to design the study concept, data interpretation, writing, reading, and final approval of the manuscript.

\section{References}

1 Zimmermann MB. The role of iodine in human growth and development. Seminars in Cell and Developmental Biology 201122 645-652. (https://doi.org/10.1016/j.semcdb.2011.07.009)

2 Glinoer D. Iodine nutrition requirements during pregnancy. Thyroid 200616 947-948. (https://doi.org/10.1089/thy.2006.16.947)

3 Leung AM, Pearce EN \& Braverman LE. Iodine nutrition in pregnancy and lactation. Endocrinology and Metabolism Clinics of North America 201140 765-777. (https://doi.org/10.1016/j.ecl.2011.08.001)

4 Pearce EN, Lazarus JH, Moreno-Reyes R \& Zimmermann MB. Consequences of iodine deficiency and excess in pregnant women: an overview of current known and unknowns. American Journal of Clinical Nutrition 2016104 (Supplement 3) 918S-923S. (https://doi. org/10.3945/ajcn.115.110429)

5 Zimmermann MB. The effects of iodine deficiency in pregnancy and infancy. Paediatric and Perinatal Epidemiology 201226 (Supplement 1) 108-117. (https://doi.org/10.1111/j.1365-3016.2012.01275.x)

6 Bath SC, Steer CD, Golding J, Emmett P \& Rayman MP. Effect of inadequate iodine status in UK pregnant women on cognitive outcomes in their children: results from the Avon Longitudinal Study of Parents and Children (ALSPAC). Lancet 2013382 331-337. (https://doi.org/10.1016/S0140-6736(13)60436-5)

7 Andersson M, Aeberli I, Wust N, Piacenza AM, Bucher T, Henschen I, Haldimann M \& Zimmermann MB. The Swiss iodized salt program provides adequate iodine for school children and pregnant women, but weaning infants not receiving iodine-containing complementary foods as well as their mothers are iodine deficient. Journal of Clinical Endocrinology and Metabolism 201095 5217-5224. (https://doi. org/10.1210/jc.2010-0975)

8 Delshad H, Touhidi M, Abdollahi Z, Hedayati M, Salehi F \& Azizi F. Inadequate iodine nutrition of pregnant women in an area of iodine sufficiency. Journal of Endocrinological Investigation 201639 755-762. (https://doi.org/10.1007/s40618-016-0438-4)

9 Zhang H, Lv S, Mu Z, Li W, Zhang X, Wang Y \& Rutherford S. Iodised salt contribution to iodine nutrition status of pregnant and lactating women. British Journal of Nutrition 2015114 126-133. (https://doi. org/10.1017/S0007114515001543) 
10 Stagnaro-Green A, Abalovich M, Alexander E, Azizi F, Mestman J, Negro R, Nixon A, Pearce EN, Soldin OP, Sullivan S et al. Guidelines of the American Thyroid Association for the diagnosis and management of thyroid disease during pregnancy and postpartum Thyroid 201121 1081-1125. (https://doi.org/10.1089/thy.2011.0087)

11 De Groot L, Abalovich M, Alexander EK, Amino N, Barbour L, Cobin RH, Eastman CJ, Lazarus JH, Luton D, Mandel SJ et al. Management of thyroid dysfunction during pregnancy and postpartum: an Endocrine Society clinical practice guideline. Journal of Clinical Endocrinology and Metabolism 201297 2543-2565. (https:// doi.org/10.1210/jc.2011-2803)

12 Leung AM, Pearce EN, Braverman LE \& Stagnaro-Green A. AAP recommendations on iodine nutrition during pregnancy and lactation. Pediatrics 2014134 e1282. (https://doi.org/10.1542/ peds.2014-2111A)

13 Chittimoju SB \& Pearce EN. Iodine deficiency and supplementation in pregnancy. Clinical Obstetrics and Gynecology 201962 330-338. (https://doi.org/10.1097/GRF.0000000000000428)

14 Taylor PN, Okosieme OE, Dayan CM \& Lazarus JH. Therapy of endocrine disease: impact of iodine supplementation in mild-tomoderate iodine deficiency: systematic review and meta-analysis. European Journal of Endocrinology 2014170 R1-R15. (https://doi. org/10.1530/EJE-13-0651)

15 Taylor PN \&Vaidya B. Iodine supplementation in pregnancy - is it time? Clinical Endocrinology 201685 10-14. (https://doi.org/10.1111/ cen.13065)

16 Murcia M, Rebagliato M, Iniguez C, Lopez-Espinosa MJ, Estarlich M, Plaza B, Barona-Vilar C, Espada M, Vioque J \& Ballester F. Effect of iodine supplementation during pregnancy on infant neurodevelopment at 1 year of age. American Journal of Epidemiology 2011173 804-812. (https://doi.org/10.1093/aje/kwq424)

17 Rebagliato M, Murcia M, Alvarez-Pedrerol M, Espada M, FernandezSomoano A, Lertxundi N, Navarrete-Munoz EM, Forns J, Aranbarri A, Llop $S$ et al. Iodine supplementation during pregnancy and infant neuropsychological development. INMA Mother and Child Cohort Study. American Journal of Epidemiology 2013177 944-953. (https:// doi.org/10.1093/aje/kws333)

18 Shi X, Han C, Li C, Mao J, Wang W, Xie X, Li C, Xu B, Meng T, $\mathrm{Du} \mathrm{J}$ et al. Optimal and safe upper limits of iodine intake for early pregnancy in iodine-sufficient regions: a cross-sectional study of 7190 pregnant women in China. Journal of Clinical Endocrinology and Metabolism 2015100 1630-1638. (https://doi.org/10.1210/jc.20143704)

19 Moher D, Liberati A, Tetzlaff J, Altman DG \& PRISMA Group. Preferred reporting items for systematic reviews and meta-analyses: the PRISMA statement. PLoS Medicine 20096 e1000097. (https://doi. org/10.1371/journal.pmed.1000097)

20 Higgins JPT, Altman DG \& Sterne JAC (eds). Chapter 8: Assessing risk of bias in included studies. In Cochrane Handbook for Systematic Reviews of Interventions Version 5.2.0 (updated June 2017). Eds JPT Higgins, R Churchill, J Chandler \& MS Cumpston. Cochrane. (available at: www.training.cochrane.org/handbook)

21 Adu-Afarwuah S, Young RT, Lartey A, Okronipa H, Ashorn P, Ashorn U, Zeilani M \& Dewey KG. Supplementation during pregnancy with small-quantity lipid-based nutrient supplements or multiple micronutrients, compared with iron and folic acid, increases women's urinary iodine concentration in semiurban Ghana: a randomized controlled trial. Maternal and Child Nutrition $2018 \mathbf{1 4}$ e12570. (https://doi.org/10.1111/mcn.12570)

22 Gowachirapant S, Jaiswal N, Melse-Boonstra A, Galetti V, Stinca S, Mackenzie I, Thomas S, Thomas T, Winichagoon P, Srinivasan K et al. Effect of iodine supplementation in pregnant women on child neurodevelopment: a randomised, double-blind, placebo-controlled trial. Lancet: Diabetes and Endocrinology 20175 853-863. (https://doi. org/10.1016/S2213-8587(17)30332-7)
23 Mridha MK, Matias SL, Paul RR, Hussain S, Khan MSA, Siddiqui Z, Ullah B, Sarker M, Hossain M, Young RT et al. Daily consumption of lipid-based nutrient supplements containing $250 \mu \mathrm{g}$ iodine does not increase urinary iodine concentrations in pregnant and postpartum women in Bangladesh. Journal of Nutrition 2017 147 1586-1592. (https://doi.org/10.3945/jn.117.248963)

24 Antonangeli L, Maccherini D, Cavaliere R, Di Giulio C, Reinhardt B, Pinchera A \& Aghini-Lombardi F. Comparison of two different doses of iodide in the prevention of gestational goiter in marginal iodine deficiency: a longitudinal study. European Journal of Endocrinology 2002147 29-34. (https://doi.org/10.1530/eje.0.1470029)

25 Brucker-Davis F, Ganier-Chauliac F, Gal J, Panaia-Ferrari P, Pacini P, Fenichel P \& Hieronimus S. Neurotoxicant exposure during pregnancy is a confounder for assessment of iodine supplementation on neurodevelopment outcome. Neurotoxicology and Teratology 2015 51 45-51. (https://doi.org/10.1016/j.ntt.2015.07.009)

26 Censi S, Watutantrige-Fernando S, Groccia G, Manso J, Plebani M, Faggian D, Mion MM, Venturini R, Andrisani A, Casaro A et al. The effects of iodine supplementation in pregnancy on iodine status, thyroglobulin levels and thyroid function parameters: results from a randomized controlled clinical trial in a mild-to-moderate iodine deficiency area. Nutrients 201911 2639. (https://doi.org/10.3390/ nu11112639)

27 Glinoer D, De Nayer P, Delange F, Lemone M, Toppet V, Spehl M, Grun JP, Kinthaert J \& Lejeune B. A randomized trial for the treatment of mild iodine deficiency during pregnancy: maternal and neonatal effects. Journal of Clinical Endocrinology and Metabolism 1995 80 258-269. (https://doi.org/10.1210/jcem.80.1.7829623)

28 Hieronimus S, Ferrari P, Gal J, Berthier F, Azoulay S, Bongain A, Fenichel P \& Brucker-Davis F. Relative impact of iodine supplementation and maternal smoking on cord blood thyroglobulin in pregnant women with normal thyroid function. European Thyroid Journal 20131 264-273. (https://doi.org/10.1159/000342915)

29 Liesenkotter KP, Gopel W, Bogner U, Stach B \& Gruters A. Earliest prevention of endemic goiter by iodine supplementation during pregnancy. European Journal of Endocrinology 1996134 443-448. (https://doi.org/10.1530/eje.0.1340443)

30 Nohr SB, Jorgensen A, Pedersen KM \& Laurberg P. Postpartum thyroid dysfunction in pregnant thyroid peroxidase antibodypositive women living in an area with mild to moderate iodine deficiency: is iodine supplementation safe? Journal of Clinical Endocrinology and Metabolism 200085 3191-3198. (https://doi. org/10.1210/jcem.85.9.6799)

31 Pedersen KM, Laurberg P, Iversen E, Knudsen PR, Gregersen HE, Rasmussen OS, Larsen KR, Eriksen GM \& Johannesen PL. Amelioration of some pregnancy-associated variations in thyroid function by iodine supplementation. Journal of Clinical Endocrinology and Metabolism 199377 1078-1083. (https://doi.org/10.1210/ jcem.77.4.8408456)

32 Romano R, Jannini EA, Pepe M, Grimaldi A, Olivieri M, Spennati P, Cappa F \&D'Armiento M. The effects of iodoprophylaxis on thyroid size during pregnancy. American Journal of Obstetrics and Gynecology 1991164 482-485. (https://doi.org/10.1016/s0002-9378(11)80004-9)

33 Santiago P, Velasco I, Muela JA, Sanchez B, Martinez J, Rodriguez A, Berrio M, Gutierrez-Repiso C, Carreira M, Moreno A et al. Infant neurocognitive development is independent of the use of iodised salt or iodine supplements given during pregnancy. British Journal of Nutrition 2013110 831-839. (https://doi.org/10.1017/ S0007114512005880)

34 Velasco I, Carreira M, Santiago P, Muela JA, Garcia-Fuentes E, Sanchez-Munoz B, Garriga MJ, Gonzalez-Fernandez MC, Rodriguez A, Caballero FF et al. Effect of iodine prophylaxis during pregnancy on neurocognitive development of children during the first two years of life. Journal of Clinical Endocrinology and Metabolism 200994 3234-3241. (https://doi.org/10.1210/jc.2008-2652) 
35 Zhou SJ, Skeaff SA, Ryan P, Doyle LW, Anderson PJ, Kornman L, Mcphee AJ, Yelland LN \& Makrides M. The effect of iodine supplementation in pregnancy on early childhood neurodevelopment and clinical outcomes: results of an aborted randomised placebo-controlled trial. Trials 201516 563. (https://doi. org/10.1186/s13063-015-1080-8)

36 Iodine Global Network. Global Scorecard of Iodine Nutrition in 2017 in the General Population and in Pregnant Women (PW). Zurich, Switzerland: IGN, 2017. (available at: http://www.ign.org/cm_data/ IGN_Global_Scorecard_AllPop_and_PW_May2017.pdf)

37 Hynes KL, Seal JA, Otahal P, Oddy WH \& Burgess JR. Women remain at risk of iodine deficiency during pregnancy: the importance of iodine supplementation before conception and throughout gestation. Nutrients 201911 172. (https://doi.org/10.3390/ nu11010172)

38 Harding KB, Pena-Rosas JP, Webster AC, Yap CM, Payne BA, Ota E $\&$ De-Regil LM. Iodine supplementation for women during the preconception, pregnancy and postpartum period. Cochrane Database of Systematic Reviews 20173 Cd011761. (https://doi. org/10.1002/14651858.CD011761.pub2)
39 Kramer M, Kupka R, Subramanian SV \& Vollmer S. Association between household unavailability of iodized salt and child growth: evidence from 89 demographic and health surveys. American Journal of Clinical Nutrition 2016104 1093-1100. (https://doi.org/10.3945/ ajcn.115.124719)

40 Farebrother J, Naude CE, Nicol L, Sang Z, Yang Z, Jooste PL, Andersson M \& Zimmermann MB. Effects of iodized salt and iodine supplements on prenatal and postnatal growth: A systematic review. Advances in Nutrition 20189 219-237. (https://doi.org/10.1093/ advances/nmy009)

41 Nazeri P, Shab-Bidar S, Pearce EN \& Shariat M. Do maternal urinary iodine concentration or thyroid hormones within the normal range during pregnancy affect growth parameters at birth? A systematic review and meta-analysis. Nutrition Reviews 202078 747-763. (https://doi.org/10.1093/nutrit/nuz105)

42 Levie D, Korevaar TIM, Bath SC, Murcia M, Dineva M, Llop S, Espada M, van Herwaarden AE, de Rijke YB, Ibarluzea JM et al. Association of maternal iodine status with child IQ: a meta-analysis of individual participant data. Journal of Clinical Endocrinology and Metabolism 2019 104 5957-5967. (https://doi.org/10.1210/jc.2018-02559)

Received 13 August 2020

Revised version received 14 September 2020

Accepted 29 September 2020 